\title{
Epidemiology and Challenges of HBV/HIV Co-Infection Amongst HIV-Infected Patients in Endemic Areas: Review
}

\section{Letebrhan Weldemhret iD \\ Medical Microbiology, Tigray Health Research Institute, Mekelle, Ethiopia}

Correspondence: Letebrhan Weldemhret Email Letinaweldemhret@gmail.com

\begin{abstract}
With the introduction of highly active antiretroviral treatment, HIV-related morbidity and mortality have declined. But underlying hepatitis B virus infection remains the major cause of AIDS-defined illness and liver-related disease progression mainly in endemic settings. Moreover, HBV-HIV co-infection is the leading cause of cirrhosis, hepatocellular carcinoma, and liver-related death. This review paper emphasizes reviewing the burden and impact of HBVHIV co-infection in liver-related disease progression, immune recovery, and therapeutic management of HIV-infected individuals on ART regimen.
\end{abstract}

Keywords: epidemiology, HBV, HIV, HBV-HIV, co-infection, patient, endemic

\section{Introduction}

Hepatitis B virus is a major global public health problem. HBV-HIV co-infection is not uncommon due to shared risk of transmission particularly in areas of endemic HBV infection. ${ }^{1}$ The risk of acquiring HBV infection in HIV-infected patients is increased by $40 \%$ compared to HIV-negative individuals. ${ }^{2} \mathrm{HBV}$ co-infection is an increased cause of morbidity and mortality among people living with $\mathrm{HIV}^{3}$ Moreover, many people living with HIV are unaware that they are infected with HBV and they are at high risk of developing liver-related disease. ${ }^{4,5} \mathrm{HBV}$ coinfection is not commonly tested prior to ART initiation despite the strong recommendation for routine screening of HBV co-infection particularly in resource-scarce settings. ${ }^{6-8} \mathrm{HBV}$ co-infection is an increased risk of liver-related disease progression and continuous non-AIDS defining morbidity in HIV-infected patients. ${ }^{3}$ The effect of HBV co-infection on HIV disease progression and liver-related complications among HIV-infected individuals on HAART has been limited and contradictory with several study findings. ${ }^{5,9,10}$ This review paper was aimed to summarize the epidemiology and complication of HBV-HIV co-infection in people living with HIV.

\section{Epidemiology of HBV}

Approximately 2 billion people are infected with HBV, and of these 400 million people developed chronic hepatitis $B$ infection worldwide. ${ }^{6,11}$ In addition, about 1 million people die annually from HBV-related disease despite the availability of vaccine and antiviral therapy which is challenging the global strategy for viral hepatitis reduction of new viral hepatitis by $90 \%$ and to reduce deaths due to viral 
hepatitis by $65 \%$ by $2030 ._{-}^{7}$ The distribution of HBV infection and pattern of transmission varies throughout the world. ${ }^{12}$ Hepatitis B virus is highly endemic in developing regions which accounted for approximately $8 \%$ for chronic carriers and $70-95 \%$ with past or current serological markers of HBV infection in the general population. ${ }^{4}$

The prevalence of HBV infection ranges from $0.1 \%$ to $20 \%$ worldwide mainly due to the age difference at the time of infection. ${ }^{13}$ Moreover, $45 \%$ of the world population live in endemic areas for chronic HBV infection, $43 \%$ live in intermediate-endemicity, and $12 \%$ live in low-endemicity areas. ${ }^{5}$ The global prevalence of HBV infection in high, intermediate, and low endemic areas is $\geq 8 \%, 2-7 \%$, and $<2 \%$ respectively. ${ }^{11}$ In most developed countries, the prevalence of chronic HBV infection is less than $1 \%$, and infection is acquired during adulthood mainly due to sexual and parenteral causes. However, in developing regions like Asia, Africa, and Western Pacific, the prevalence of chronic HBV infection is more than $8 \%$ and infection is acquired either perinatal or during childhood. ${ }^{6,7,12}$ The prevalence of $\mathrm{HBV}$ is estimated to be $8 \%$ in Western Africa and 5-7\% in Southern and Eastern Africa. ${ }^{11}$ In Africa, the most predominant HBV genotypes are A, D, and E. ${ }^{8,10,14}$ Genotype $\mathrm{A}$ is the most frequently detected and accompanied by the majority of the HBV subtypes. ${ }^{8,15-17}$

\section{HBV-HIV Coinfection}

Globally, approximately 35.3 million people are living with HIV. ${ }^{18}$ Of these, 4 million HIV-positive individuals are coinfected with HBV worldwide. ${ }^{19}$ The global prevalence of HBV-HIV co-infection among HIV-infected individuals is $7.4 \%{ }^{7}$ In Africa, it is estimated that 3.4 million people are co-infected with HBV and HIV with a proportion of $15 \%{ }^{2}$ Moreover, approximately $90 \%$ of HIV-infected individuals have biological signs of prior HBV infection, and of these, 5$15 \%$ suffered from chronic HBV infection. ${ }^{4}$ The proportion and risk factors of HBV-HIV co-infection vary widely with geographical distribution. ${ }^{2,19,20}$ The prevalence of HBVHIV co-infection in Western Europe and North America is estimated to be $5 \%$ whereas in developing regions like South East Asia it is about $20 \% .{ }^{19}$ Moreover, the prevalence of HBV-HIV co-infection in Africa ranges from $2 \%$ to $30.6 \%$ with different studies. ${ }^{7,17,21-26}$

\section{HBV-HBD-HIV Co-infection}

Hepatitis D virus infection occurs only in the presence of active HBV infection (defined by the presence of HBsAg). This infection occurs either simultaneously or as superinfection with $\mathrm{HBV}^{7}$ Liver-related disease progression is faster in HBV-HDV-HIV co-infected individuals than HIV-negative. ${ }^{14,27} \mathrm{HDV}$ affected $5 \%$ of people who have chronic HB infection, which implies 1 in 5 cases of liver disease and liver cancer in people with HBV infection. ${ }_{-}^{7}$ HBV-HDV co-infection is considered the most severe form of chronic viral hepatitis that leads to more rapid progression toward liver-related death and HCC. ${ }^{7,14}$ In Africa, HBV-HDV co-infection is more prevalent in western and middle African countries. ${ }^{4,6,28}$ The proportion of triple infection (HBV-HDV-HIV) ranges from $1.4 \%$ to $19.7 \%$ among HIV patients on ART follow up in different countries..$^{14,16,17,7,27}$

\section{Hepatocellular Carcinoma}

The risk of hepatocellular carcinoma (HCC) is increased by 5 or 6 fold among HIV-infected individuals, particularly in those on ART, compared to the general population. ${ }^{7}$ This is characterized by the presence of low $\mathrm{CD} 4{ }^{+} \mathrm{T}$ cells, and high HBV DNA level. HBV-HIV co-infected individuals have shown persistent viral (HBV DNA) replication with increased risk of end stage liver disease and hepatocellular carcinoma than HBV mono-infected patients. ${ }^{16,29}$ Moreover, the progression of chronic HBV to cirrhosis, end stage liver disease, and hepatocellular carcinoma is greater in HBV-HIV co-infected subjects. ${ }^{10}$

\section{HBV Specific Immune Response}

Cell-mediated immunity and inflammation play an important role in symptomatic cases and resolution of HBV infection. ${ }^{30}$ The outcome of HBV infection mainly depends on the host-virus interaction mediated by the adaptive immune response. ${ }^{31}$ But, the host factor is less known in the progression of the disease. The virus-specific $\mathrm{T}$ cell response is one of the key factors in the pathogenesis of HBV infection. ${ }^{30}$ Acute or chronic hepatitis $\mathrm{B}$ infection causes liver disease as a result of subsequent activation of cytotoxic $\mathrm{T}$ cells and cytokine-mediated immune response to eliminate the infected cells. ${ }^{31}$ Chronic hepatitis B infection is indicated by the presence of a greatly reduced $\mathrm{T}$ cell response in peripheral blood cells.

Spontaneous clearance of infection from hepatitis B is indicated by the presence of detectable $\mathrm{CD}^{+} \mathrm{T}$ cell and $\mathrm{CD}^{+} \mathrm{T}$ cell response. ${ }^{31}$ Likewise, HBV specific antibodies are protective proteins and markers of the disease progression. Specific antibodies for HBsAg are lifelong protective immunity and persist in life after recovery, which is controlled by cellular and humoral immune 
response. ${ }^{31}$ In the usual course of $\mathrm{HBV}$ infection, patients may clear $\mathrm{HBeAg}$ and $\mathrm{HBsAg}$ and ultimately develop anti$\mathrm{HBe}$ and anti-HBs protective antibodies. ${ }^{32}$ Adult individuals are more susceptible for HBV infection than children because $90 \%$ of children are immune for HBV infection or develop a protective immune mechanism for HBV infection as a result of subsequent infection and vaccination. ${ }^{28}$

\section{Impact of HBV on CD4 Cell Recovery and HIV Disease Progression}

Many studies described that HBV-HIV co-infected individuals have shown declined or impaired CD4 cell count compared to HIV mono-infected. ${ }^{24-26,29,33}$ Higher HBV DNA (viral replication) is observed in HBV-HIV co-infected subjects with low CD4 cell count or advanced HIV/AIDS stages. ${ }^{10,33}$ Moreover, many studies suggested that HBVHIV co-infected individuals have shown impaired immune response while on ART follow up compared to HIV infected alone. ${ }^{22,32,34,35}$ In contrast, one large retrospective study indicated an increased CD4 cell count in HBV-HIV co-infected individuals compared to HBV mono-infected on ART between 6 months and 4 years, although it needs further study. ${ }^{10}$

The impact of HBV co-infection on HIV disease progression is debatable with many study findings. ${ }^{1,3,10,36}$ But, the majority indicated that HBV co-infection increased the causes of mortality and AIDS defining illness which affected the course or control of HIV disease. ${ }^{1,23,34}$ Moreover, a cohort study suggested that HBV-HIV co-infected individuals are at increased risk of AIDS or death event compared to HIV infected only. ${ }^{36,37}$ Another interesting study indicated that chronic $\mathrm{HB}$ and resolved status of HBV-HIV co-infected subjects were associated with increased risk of AIDS and death particularly in those immunocompromised individuals. ${ }^{10}$ In contrast, other studies demonstrated that HBV co-infection has no impact on the natural history of HIV disease progression. ${ }^{3,9}$ Moreover, in one study, persistence immune reconstitution is observed among HBV-HIV co-infected individuals on longer ART follow up. ${ }^{10}$ To address these contradictory findings, a large well-designed prospective study is needed.

\section{Viral Suppression and HBV Reactivation}

Many findings indicated that HIV-HBV co-infected individuals have shown lower CD4 cell count compared to HIV infected alone. ${ }^{22,32,34,35}$ However, the roles of low CD4 cell count and HIV viremia in HBV-HIV co-infected individuals are unclear with many study findings. ${ }^{32,34,35}$ But one large prospective study described that HIV viral suppression at 6 months and greater with $\mathrm{HBV}$ active ART regimen reduced the risk of liver complications in HBV-HIV co-infected individuals after ART administration compared to those with elevated HIV RNA. ${ }^{38}$ This emphasizes the importance of suppressed HIV RNA for reducing liver-related complication. Likewise, early initiation of ART and optimum HIV viral suppression reduced the risk of developing end stage liver disease and hepatocellular carcinoma. ${ }^{38}$

HBV co-infected individuals have shown a low level of detectable HBsAg using serological testing, but anti-HBcAb is the best marker for HBV infections. ${ }^{23}$ Because, HIVinfected patients invariably developed occult HBV infection with undetectable HBsAg. ${ }^{23}$ Moreover, underscreening for anti-HBcAb may result in hepatic flare and increased the risk of fulminant hepatitis following combination ART due to immune reconstitution inflammatory syndrome. ${ }^{7,38,39}$ Hence, $\mathrm{HBV}$ reactivation in the absence of detectable $\mathrm{HBsAg}$ is a great challenge in HBV-HIV co-infected individuals on HBV active ART which leads to treatment interruption and emergence of $\mathrm{HBV}$ drug resistance. Emerging HBV mutants may affect the immunization strategy in the future. Therefore, HIV patients should be screened for $\mathrm{HBc}$ prior to treatment initiation. ${ }^{7,40}$ Likewise, individuals with anti-HBcAg, particularly HIV-positive people, are at increasing risk of viral reactivation and progression. ${ }^{41} \mathrm{~A}$ high and sustained serum HBV DNA level and decreased seroconversion of $\mathrm{HBeAg}$ and $\mathrm{HBsAg}$ are often seen in HBV-HIV coinfected people compared to HBV mono-infected. ${ }^{30,42}$

\section{Impact of HIV on Liver Complication}

Impaired immune response to HIV is an increased risk for liver-related disease progression among HBV-HIV coinfected patients on $\mathrm{HBV}$ active ART regimen. ${ }^{7,28,38}$ Moreover, the rate of HBV-HIV co-infection is increased in HIV patients with impaired immune response compared to individuals with optimum immune restoration. ${ }^{23,32,34,43}$ The proportion of liver-related mortality is higher among HBVHIV co-infected subjects than HBV mono-infected only. ${ }^{20}$ Likewise, HIV infection increased the risk of rapid progression of liver-related disease in patients with chronic HBV infection. ${ }^{5,20,25,26}$ The rate of acquiring chronic HBV infection among the HBV-HIV co-infected individuals and those infected with $\mathrm{HBV}$ alone is $25 \%$ and $4 \%$ respectively. ${ }^{42}$ 
Unlike the above findings, one prospective study suggested HBV-HIV co-infected patients are less likely to develop liver disease progression than HBV mono-infected, particularly among those with non-AIDS stages. ${ }^{17}$

\section{Therapeutic Management}

The most common and advisable treatment option for HBVHIV co-infection is either Lamivudine or emtricitabine with tenofovir combination ART regimen. ${ }^{39,40}$ A tenofovir-based combination ART regimen is preferable drug for HBV-HIV co-infected patients with better treatment outcome and low HBV DNA drug resistance. ${ }^{34,40,41}$ One case report from Ethiopia suggested that a tenofovir-based combination ART regimen has shown optimum immune restoration and significant viral suppression to an undetectable level compared to only a Lamivudine-containing ART regimen. ${ }^{37}$

The majority of studies indicated that a TDF-containing combination ART regimen is the most common and effective drug for HBV-HIV co-infection. ${ }^{7,20,23,43}$ The risk of liver complication is also reduced with ART that included TDF antiretroviral for HBV-HIV co-infection. ${ }^{38}$ The majority (80.7\%) of HIV patients positive for HBsAg were taking a TDF-containing first-line ART combination regimen in subSaharan Africa. ${ }^{24}$ Moreover, the World Health Organization recommended screening of all HIV-infected individuals for HBV for appropriate choice of ART regimen and vaccinations for non-immunized individuals. ${ }^{40}$ One study in Cameroon described that only $33.3 \%$ of HBV-HIV co-infected subjects expressed undetectable HBV DNA after commencement of a Lamivudine (3TC)-containing combination ART regimen and $100 \%$ of undetectable HBV DNA in subjects who were administered a TDF-3TC-containing ART regimen. ${ }^{17}$ Unlike the above findings, a study in Mozambique indicated that an anti-HBV drug-containing combination ART regimen revealed persistent $\mathrm{HBV}$ viral replication compared to $\mathrm{HBV}$ mono-infected on anti-HBV treatment follow up. ${ }^{16}$ This implies the efficacy of HBV active ART regimen is decreased among HBV-HIV co-infected individuals than HBV monoinfected on anti-HBV drugs, although it needs further additional evidence.

\section{TC Resistance-Associated Mutations}

Patients who were taking 3TC anti-HBV drug are more likely at increased risk of incomplete HBV viral suppression. ${ }^{17,39,41}$ One study indicated that HBV resistance mutation for 3TC is acquired after the patients were taking ART regimen, and no resistance HBV mutant was identified in naïve ART patients. ${ }^{16}$ In addition, high baseline HBV DNA is a significant factor for drug resistance mutation following $\mathrm{HBV}$ active ART regimen. ${ }^{39}$ Mutation to lamivudine is usually observed in chronic HBV co-infected individuals who were positive for HBeAg. ${ }^{15,42}$

A study report in Cameroon indicated that $25 \%$ of patients on 3TC HBV active ART harbored (acquired) resistance to $3 \mathrm{TC} .{ }^{17}$ Moreover, other prospective studies indicated that $53.8 \%$ of HBV-HIV co-infected patients who were taking a 3TC combination ART regimen without TDF were associated with HBV drug resistance mutation. ${ }^{15,17}$ In contrast, one study indicated that a Lamivudine-containing ART regimen in HBV-HIV co-infected individuals on prolonged treatment follow up revealed persistent HBV viral suppression. ${ }^{44}$ With this report, mutant resistance strain to 3TC was not observed before commencement of HAART. ${ }^{44}$ Therefore, resistance to 3TC may be acquired due to subsequent uptake of a 3TC-containing ART regimen. Other findings also indicated that a combination ART regimen increased the risk of acquiring HBV drug resistance and liver complication in HBV-HIV co-infected subjects unlike those individuals on anti-HBV drug only.

However, one retrospective study indicated that the majority of HBV-HIV co-infected individuals who were on aTDF-based combination ART regimen failed to achieve HBV viral suppression during the first years of follow up. ${ }^{39}$ But this might not have anegative impact on patient management since treatmentsfor both HBV and HIV are lifelong and viral suppression may be achieved in defer follow ups. Besides, one literature review indicated that detectable HBV DNA was observed in $10 \%$ of HBV-HIV co-infected individuals who were taking aTDFcontaining ART regimen. ${ }^{20}$ Although many national and international findings recommended tenofovir for HBVHIV co-infection, the above findings emphasized the need to prove other safe and potent anti-HBVdrugs..$^{39,40}$

\section{Conclusions}

The burden of HBV-HIV co-infection is found higher in different studies in HBV endemic settings. HBV-HIV coinfection remains a significant factor for liver-related complications and non-AIDS related death. HBV-HIV co-infection accelerated the disease progression to AIDS defining illness in HBV co-infected subjects. Likewise, HBV specific immune response is impaired with declined $\mathrm{CD} 4^{+} \mathrm{T}$ cell response in HBV-HIV co-infected individuals. On the other hand, HIVinfected individuals with immunocompromised are at increased risk of reverse seroconversion or reactivation for HBV infection. Moreover, in most resource-scarce 
settings the screening strategy for $\mathrm{HBV}$ is based on the presence or absence of circulating HBsAg, but this may lose the active cases of HBV infection which leads liver-related chronic infection and drug toxicity. Therefore, all HIVpositive individuals shall be screened for HBV DNA level for proper selection of combination ART regimen. HBV coinfection still accelerated the liver disease progression in HIVinfected individuals who are on HBV active ART regimen. This is an implication to explore more potent and effective drugs onward for HBV and HIV co-infected individuals.

\section{Ethics Approval and Informed Consent}

The data used for this review paper are published articles which are open public in the web. Therefore, ethical approval and informed consent are non-applicable.

\section{Consent for Publication}

Not applicable.

\section{Author Contributions}

The author made a significant contribution to the work reported, whether that is in the conception, study design, execution, acquisition of data, analysis and interpretation, or in all these areas; took part in drafting, revising or critically reviewing the article; gave final approval of the version to be published; have agreed on the journal to which the article has been submitted; and agree to be accountable for all aspects of the work.

\section{Funding}

There is no funding to report for this study.

\section{Disclosure}

The author declared no competing interests.

\section{References}

1. Barth RE, Huijgen Q, Taljaard J, Hoepelman IM. Hepatitis B/C and HIV in sub-Saharan Africa: an association between highly prevalent infectious diseases. A systematic review and meta-analysis. Int $J$ Infectious Diseases. 2010;14:e1024-e1031. doi:10.1016/j. ijid.2010.06.013

2. World Health Organization. Management of hepatitis B and HIV co infection. 2011. Available from: http://www.euro.who.int/ data/assets/pdf_file/0011/152012/e95792.pdf. Accessed April 23, 2021.

3. Alberti A, Clumeck N, Collins S, et al. Short statement of the first European consensus conference on the treatment of chronic Hepatitis B and C in HIV Co infected patients. J Hepatol. 2005;42:615-624. doi:10.1016/j.jhep.2005.03.003
4. Alter M. Epidemiology of viral hepatitis and HIV co-infection. J Hepathology. 2006;44:S6-9.

5. World Health Organization. Prevention and control of viral hepatitis infection. Available from: https://apps.who.int/iris/handle/10665/ 130012. Accessed April 26, 2021

6. Lacombe K, Rockstroh J. HIV and viral hepatitis co infections: advances and challenges. Gut. 2004;61(1):i47ei58.

7. World Health Organization. Global health sector strategy on viral hepatitis 2016-2021. Available from: https://www.who.int/hepatitis/ strategy2016-2021/ghss-hep/en/. Accessed April 23, 2021.

8. UNAIDS, Joint United Nations Programme on HIV/AIDS. Seizing the moment - Tackling entrenched in equalities to end epidemics. Geneva: UNAIDS; 2020. Available from: https://www.un.org/sexual violenceinconflict/wp-content/uploads/2020/07/report/global-aidsupdate-seizing-the-moment-tackling-entrenched-inequalities-to-endepidemics/2020_global-aids-report_en.pdf. Accessed 29.04.2021.

9. Modi A, Feld J. Viral hepatitis and HIV in Africa. AIDS Review. 2007;9:25-39.

10. Chun HM, Mesner O, Thio C, et al. HIV outcomes in Hepatitis B virus coinfected individuals on HAART. J Acquir Immune Defic Syndr. 2014;66(2):197-205. doi:10.1097/QAI.000000000000142

11. McMahon BJ. Epidemiology and natural history of hepatitis B. Semin Liver Dis. 2005;25(1):3-8. doi:10.1055/s-2005-915644

12. World Health Organization. UNAIDS report on the global AIDS epidemic 2013. 2013; Available from: https://www.who.int/hiv/pub/ me/unaids_global_report/en/. Accessed April 23, 2021.

13. Valla D. EASL International Consensus Conference of Hepatitis B, 13-14 September, 2002 Geneva, Switzerland. J Hepatol. 2003;38:533-540.

14. Motamedifar M, Taheri M, Lankarani KB, et al. The prevalence and risk factors of hepatitis delta virus in HIV/HBV Co-Infected Patients in Shiraz, Iran, 2012. Iran J Med Sci September. 2015;40(5).

15. Deressa T, Damtie D, Fonseca K, et al. The burden of hepatitis B virus (HBV) infection, genotypes and drug resistance mutations in human immunodeficiency virus positive patients in Northwest Ethiopia. PLoS One. 2017;12(12):e0190149. doi:10.1371/journal.pone.0190149

16. Chambal LM, SamoGudo E, Carimo A, et al. HBV infection in untreated HIV-infected adults in Maputo, Mozambique.2017. PLoS One. 2017;12(7):e0181836. doi:10.1371/journal.pone.0181836

17. Salpini R, Fokam J, Ceccarelli L, et al. High Burden of HBV-Infection and Atypical HBV Strains Among HIV Infected Cameroonians. Curr HIV Res. 2016;14. doi:10.2174/ $1570162 X 13666150930114742$

18. Sorianoa V, Puotib M, Bonacinic M, et al. Care of patients with chronic hepatitis B and HIV co-infection: recommendations from an HIV-HBV International Panel. AIDS. 2005;19:221-240.

19. Soriano V, Barreiro P, Nunez M. Management of chronic hepatitis $\mathrm{B}$ and $\mathrm{C}$ in HIV-co infected patients. J Antimicrobial Chemotherapy. 2006;57:815-818. doi:10.1093/jac/dk1068

20. Singh KP, Crane M, Audsley J, Lewin SR. HIV-Hepatitis B virus co-infection: epidemiology, pathogenesis and treatment. AIDS. 2017;31(15):2035-2052. doi:10.1097/QAD.0000000000001574

21. Alo MN, Alhassan HM, Saidu AY, Ugah UI, Umar FA. Cd4 T cell count in patients concomitantly infected with HIV and Hepatitis B Virus in Sokoto State, Nigeria. World J Medical Sciences. 2013;8(3):296-299.

22. Ethiopian Public Health Institute. Ethiopia population-based HIV impact assessment (EPHIA) 2017-2018.Available from: https://phia. icap.columbia.edu/wp-content/uploads/2020/11/EPHIA_Report_ 280820_High-Res.pdf. Accessed April 23, 2021.

23. Ayana DA, Mulu A, Mihret A, et al. Hepatitis B virus seromarkers among HIV infected adults on ART: an unmet need for HBV screening in eastern Ethiopia. PLoS One. 2019;14(12):e0226922.

24. Pappoe F, Hagan CKO, Yeboah DO. Sero-prevalence of hepatitis $\mathrm{B}$ and $\mathrm{C}$ viral infections in Ghanaian HIV positive cohort: a consideration for their health care. BMC Infect Dis. 2019;19:380. doi:10.1186/s12879-019-4027-y 
25. Gede Foundation. Seroprevalence of hepatitis B and $\mathrm{C}$ infection among the HIV-positive population in Abuja, Nigeria. Afr Health Sci. 2012;12(3):312-317. doi:10.4314/ahs.v12i3.10.

26. Ogwu-Richard SO, Ojo DA, Akingbade OA, Okonko IO. Triple positivity of HBsAg, anti-HCV antibody, and HIV and their influence on CD4+ lymphocyte levels in the highly HIV infected population of Abeokuta, Nigeria. Afr Health Sci. 2015;15(3):719. doi:10.4314/ahs.v15i3.4

27. Coffie PA, Tchounga BK, Bado G, et al. Prevalence of hepatitis $\mathrm{B}$ and delta according to HIV-type: a multi-country cross-sectional survey in West Africa. BMC Infect Dis. 2017;17:466. doi:10.1186/ s12879-017-2568-5

28. Chonco F, Rangiah S. Susceptibility to hepatitis B infection, hepatitis B/HIV co-infections and hepatitis B immunity in HIV-positive patients starting HAART in Durban, South Africa. South African Family Practice. 2019;61(2):65-68. doi:10.1080/20786190.2018. 1518023

29. Matthews PC, Beloukas A, Malik A, et al. Prevalence and characteristics of Hepatitis B Virus (HBV) Coinfection among HIV-Positive Women in South Africa and Botswana. PLoS One. 2015;10(7): e0134037. doi:10.1371/journal.pone.0134037

30. Lok A, McMahon B. Chronic Hepatitis B. Hepatology. 2007;45:2.

31. Rehermann B, Nascimbeni M. Immunology of Hepatitis B virus and Hepatitis $\mathrm{C}$ virus infection. Nature Reviews Immunology. 2005;5:215-229. doi:10.1038/nri1573

32. Shimelis T, Tassachew Y, Tadewos A, et al. Coinfections with hepatitis $\mathrm{B}$ and $\mathrm{C}$ virus and syphilis among HIV-infected clients in Southern Ethiopia: a cross-sectional study. HIV/AIDS HIV/AIDS Research Palliative Care. 2017;9:203-210. doi:10.2147/HIV. $\mathrm{S} 150795$

33. Thio C, Lsmeaton L, Saulynas M, et al. Characterization of HIV-HBV co-infection in a multi-national HIVinfected cohort. AIDS. 2013;27(2):191-201. doi:10.1097/QAD.0b013e32835a9984

34. Abera B, Zenebe Y, Mulu W, Kibret M, Kahsu G. Sero prevalence of hepatitis $\mathrm{B}$ and $\mathrm{C}$ viruses and risk factors in HIV infected children at Felegehiwot referral hospital, Ethiopia. BMC Res Notes. 2014;7:83.

35. Chang JJ, Sirivichayakul S, Avihingsanon A, et al. Impaired quality of the Hepatitis B Virus (HBV)-Specific T-cell response in human immunodeficiency virus type $1-\mathrm{HBV}$ co infection. $J$ Virol. 2009;7649-7765.

36. Chun HM, Roediger MP, Hullsiek KH, et al. Hepatitis B Virus coinfection negatively impacts HIV outcomes in HIV seroconverters. J Infect Dis. 2012;205:185-193.

37. Drake A, Mijch A, Sasadeusz J. Immune reconstitution Hepatitis in HIV and Hepatitis B coinfection, despite lamivudine therapy as part of HAART. HIV/AIDS CID. 2004;39.

38. Re VL, Newcomb CW, Carbonari DM, et al. Determinants of liver complications among HIV/Hepatitis B virus-coinfected patients. J Acquir Immune Defic Syndr. 2019;82(1):71-80. doi:10.1097/ QAI.0000000000002094

39. Hafkin JS, Osborn MK, Localio AR, et al. Incidence and risk factors for incomplete HBV DNA Suppression in HIV/HBV-coinfected patients initiating tenofovir based therapy. J Viral Hepat. 2014;21 (4):288-296. doi:10.1111/jvh. 12142

40. World Health Organization. Consolidated guidelines on the use of antiretroviral drugs for treating and preventing HIV infection. Recommendation for public health approach. Geneva:WHO; 2016. Available from www.who.int. Accessed November 5, 2020.

41. Mauss S, Berg T, Rockstroh J, Sarrazin C, Wedemeyer H. Hepatology Clinical Hand Book. 4th ed. flying publisher; 2013:69-77.

42. Cheruvu S, Marks K, Talal AH. Understanding the pathogenesis and management of Hepatitis B/HIV and Hepatitis B/Hepatitis C virus co infection. Clinical Liver Disease. 2007;11:917-943.

43. Weldemhret L, Asmelash T, Belodu R, Gebreegziabiher D. Seroprevalence of HBV and associated risk factors among HIV positive individuals attending ART clinic at Mekelle hospital, Tigray, Northern Ethiopia. AIDS Res Ther. 2016;13(1):6.

44. Khamduang W, Graffin CG, Huong NNG, et al. Long-term Hepatitis $\mathrm{B}$ Virus (HBV) response to lamivudine-containing highly active antiretroviral therapy in HIV-HBV co-infected patients in Thailand. PLoS One. 2012;7(7):e42184. doi:10.1371/journal.pone.0042184
HIV/AIDS - Research and Palliative Care

\section{Publish your work in this journal}

HIV/AIDS - Research and Palliative Care is an international, peerreviewed open-access journal focusing on advances in research in HIV, its clinical progression and management options including antiviral treatment, palliative care and public healthcare policies to control viral spread. The manuscript management system is completely online and includes a very quick and fair peer-review system, which is all easy to use. Visit http://www.dovepress.com/testimonials.php to read real quotes from published authors. 